\title{
The Study of Homogeneous Populations of Caulobacter Stalked (Mother) Cells
}

\author{
By U. SWOBODA AND C. S. DOW \\ Department of Biological Sciences, University of Warwick, Coventry CV4 7AL
}

(Received 20 November 1978)

\begin{abstract}
An experimental procedure is described which facilitates the study of homogeneous populations of Caulobacter stalked (mother) cells. These populations are derived from synchronized swarm cell cultures, the preparation of which is described. From this study it appears that cross-band formation in Caulobacter NCIB 9083 is not linked to the reproductive cell cycle.
\end{abstract}

\section{INTRODUCTION}

Caulobacter species provide a convenient system by which the control of cellular morphogenesis and differentiation can be investigated (Kurn \& Shapiro, 1975).

The life cycle of Caulobacter (Poindexter, 1964) is unique in that the vegetative cell cycle consists of two distinct cell types, a motile swarm cell and a non-motile stalked cell (Fig. 1). The swarm cell loses its flagellum and develops a stalk (prostheca) at the site of the former flagellum attachment. This is followed by cell elongation and asymmetric cell division, which is by transverse binary fission, giving rise to a new swarm cell (or daughter cell) and a basal stalked cell (or mother cell). Subsequent turns of the cell cycle are out of phase in that the stalked cell forms a second cell (daughter cell) immediately, while the swarm cell first synthesizes a prostheca before becoming a reproductive cell, i.e. the immature swarm cell passes through an obligate differentiation sequence before cell reproduction.

Any study of an organized sequence of events during the microbial cell cycle requires populations of cells that are at the same stage in the life cycle, thus leading to amplification of the biochemical/molecular events occurring in a single cell. In the case of Caulobacter, synchronized populations can be obtained by selecting for either newly formed swarm cells (Shapiro et al., 1971; Newton, 1972) or stalked cells (Shapiro, 1976), although it is advantageous to select for swarmers since they form the first stage in the life cycle. However, because of the difficulty in maintaining a homogeneous population of stalked cells, only the swarm cell cycle has been studied extensively. We report here a method of maintaining and studying a homogeneous population of stalked cells and observations on cross-band formation in the stalk.

The question of the function of the stalk in the cell cycle is still unanswered (Wood \& Shapiro, 1975). Cross-bands occur at intervals along the stalk and it has been reported (Staley \& Jordan, 1973) that these serve as generation markers, a cross-band being synthesized during each turn of the mother cell cycle.

\section{METHODS}

Organism and growth conditions. Caulobacter NCIB 9083 was grown at $30^{\circ} \mathrm{C}$ in complex medium pye (Poindexter, 1964). Liquid cultures for synchronization were grown with constant stirring.

Isolation of swarm cells. An early exponential phase culture $\left(300 \mathrm{ml} ; 2 \times 10^{7}\right.$ to $\left.3 \times 10^{7} \mathrm{cells}^{-1}\right)$ was centrifuged at $6000 \mathrm{rev} . \mathrm{min}^{-1}$ in an MSE Multex centrifuge for $5 \mathrm{~min}$ and the cells were resuspended in 15 to $20 \mathrm{ml}$ preconditioned medium (Helmstetter, 1969). This suspension was aseptically filtered through a 


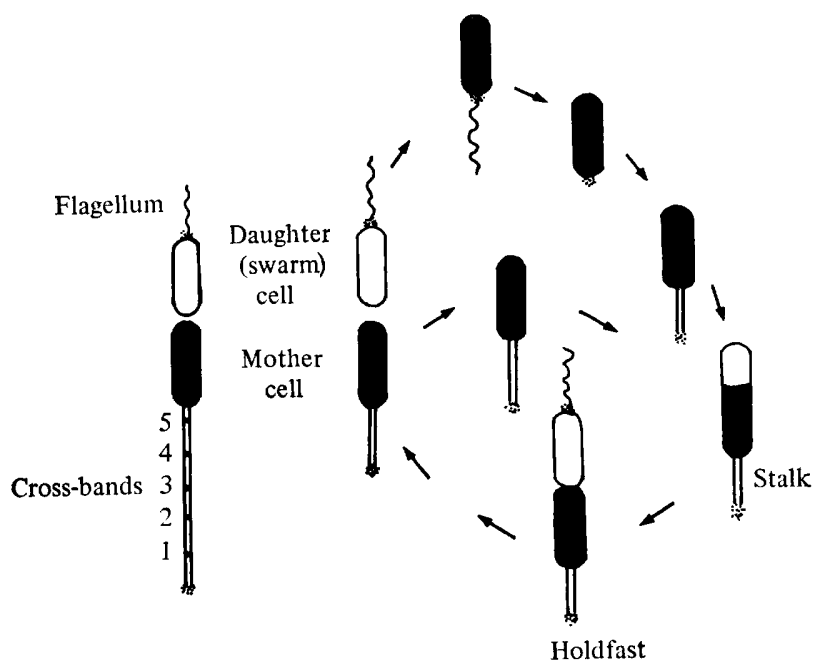

Fig. 1. The cell cycle of Caulobacter.

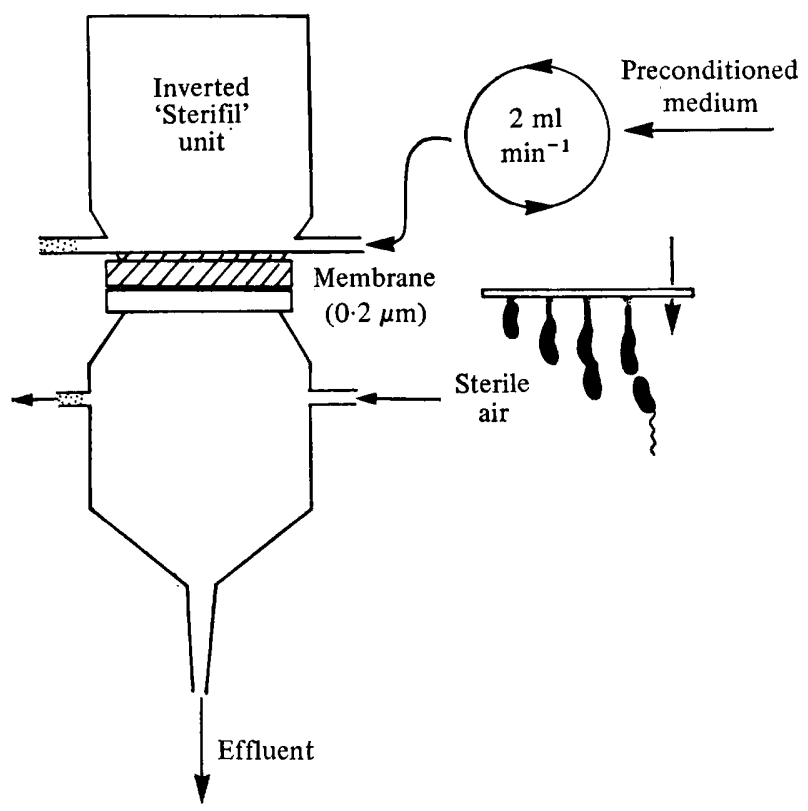

Fig. 2. Apparatus used to study stalk synthesis and cross-band formation in Caulobacter NCIB 9083.

$5 \mu \mathrm{m}$ Triacetate Metricel filter (Gelman Hawkesley Ltd, Lancing, Sussex) held in a Millipore 'Sterifil' unit. Stalked cells were retained on the filter while the swarm cells passed through. The filtrate was checked quickly for the degree of synchrony using a light microscope and a Coulter electronic particle counter/ particle distribution analyser before using it in any synchronous growth studies.

Relationship between stalk synthesis, cross-band formation and life cycle. Synchronized swarm cells were allowed to attach by their holdfasts to a $\mathbf{0} \cdot \mathbf{2} \mu \mathrm{m}$ Triacetate Metricel membrane filter in a modified 'Sterifil' unit and then the unit was inverted (Fig. 2). Preconditioned medium was passed through the filter, rapidly for the first $2 \mathrm{~min}$ (to wash out all the unbound and weakly bound cells) and then at a flow rate of $2 \mathrm{ml} \mathrm{min}^{-1}$. Effluent samples $(1 \mathrm{ml})$ were collected every $15 \mathrm{~min}$ and fixed in $0.02 \mathrm{M}$-Tris $/ 0.3 \%(\mathrm{v} / \mathrm{v})$ glutaraldehyde before determining the cell number. After $6 \mathrm{~h}$ the cells attached to the membrane were carefully removed, washed and prepared for electron microscopy using either $0.5 \%(\mathrm{w} / \mathrm{v})$ uranyl acetate negative stain or gold/palladium shadow. Cells were examined using an AEI Corinth 275' electron microscope. 


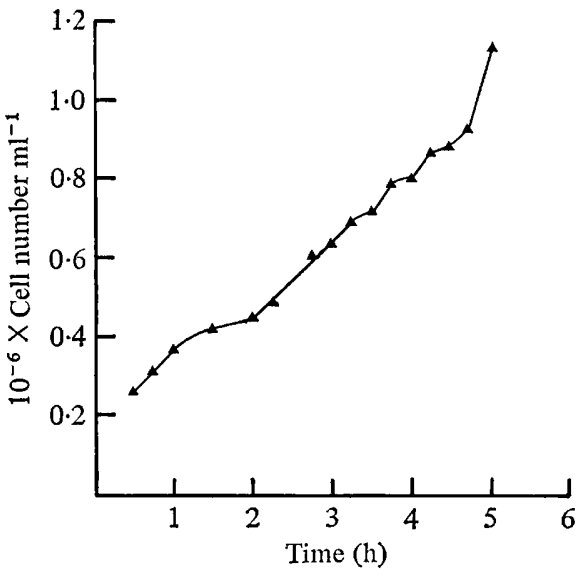

Fig. 3

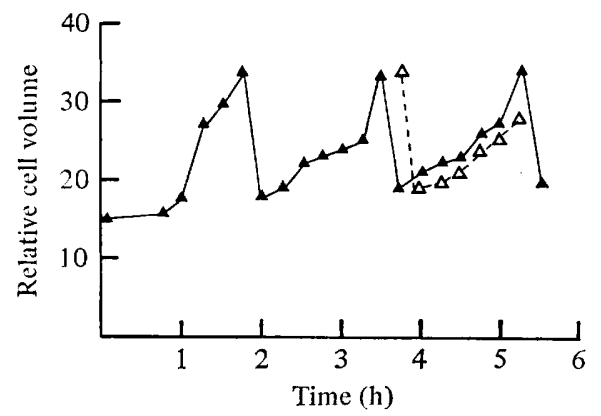

Fig. 4

Fig. 3. Growth and development of a synchronized swarm cell population of Caulobacter NCIB 9083. Cell number was determined by total particle count using a ZBI Coulter counter. The first division was completed at $1.75 \mathrm{~h}$, the second division of stalked cells was completed at $3.25 \mathrm{~h}$ and the first division of daughter cells produced by $1.75 \mathrm{~h}$ was completed at $3.75 \mathrm{~h}$. Mean generation times were $1.75 \mathrm{~h}$ for swarm cells and $1.5 \mathrm{~h}$ for stalked cells.

Fig. 4. Change in relative cell volume during growth of a synchronized culture of Caulobacter NCIB 9083 swarm cells as determined by electronic particle counting and cell volume distribution analysis. Changes in the cell volume of the initial swarm cell population $(\Delta)$ and of the first generation swarm cells $(\triangle)$ were followed.

To investigate the production of cross-bands with respect to generation time, a synchronized culture was inoculated into a $250 \mathrm{ml}$ Erlenmeyer flask containing $50 \mathrm{ml}$ medium. The culture was incubated with shaking at $30{ }^{\circ} \mathrm{C}$ and samples were removed at regular intervals. Part of each sample was used for electron microscopy. In order to overcome any doubt concerning the preparation of samples for electron microscopy, three different methods were employed: (i) staining with $0.5 \%(\mathrm{w} / \mathrm{v})$ uranyl acetate; (ii) staining with Lugol's iodine (Staley \& Jordan, 1973); (iii) shadowing with gold/palladium.

\section{RESULTS AND DISCUSSION}

\section{Synchronous culture}

Synchronized populations of Caulobacter NCIB 9083 were obtained by using a filtration technique (Fig. 2) to select cells of the same size and thus at the same point in the cell cycle. The synchronous growth curve (Fig. 3), as determined by total cell count, indicated that the first division was completed by $1.75 \mathrm{~h}$. A second wave of divisions occurred $1.5 \mathrm{~h}$ later and accounted for an approximate $50 \%$ increase in cell numbers. This was attributed to the division of the first generation stalked cells. The third wave of divisions was attributed to the division of the first generation swarm cells, i.e. those produced after $1.75 \mathrm{~h}$. In addition to the one-step growth curve, cell volume distribution profiles (Fig. 4) also indicated a high degree of synchrony. The changes in cell volume corresponded with the division times determined from the growth curve.

Physiological disturbance during filtration was kept to a minimum by using only one filter, by reducing the time of the initial centrifugation step to a minimum and by using preconditioned medium throughout.

\section{Homogeneous stalked (mother) cell populations}

Synchronized swarm cells, attached by their holdfasts to an inverted membrane, differentiated to become stalked mother cells. Newly formed swarm cells were released into the medium at regular intervals (Fig. 5). Particle counts of the effluent of the modified 'Sterifil' 


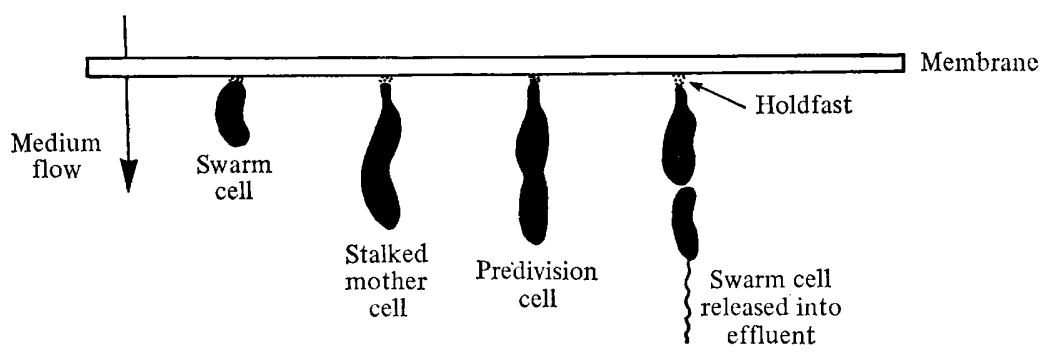

Fig. 5. The successive stages in the life cycle of an individual Caulobacter cell attached to a membrane filter, leading to the elution of the daughter cell.

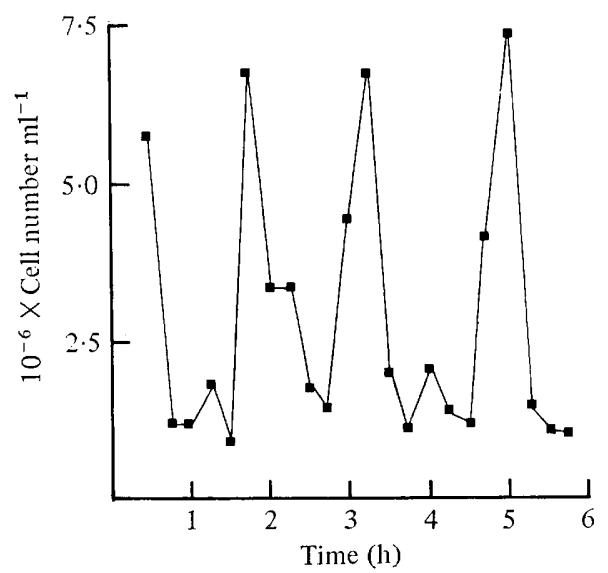

Fig. 6. Particle counts (swarm cells) of the effluent from the inverted membrane showing sequential waves of swarm cell production.

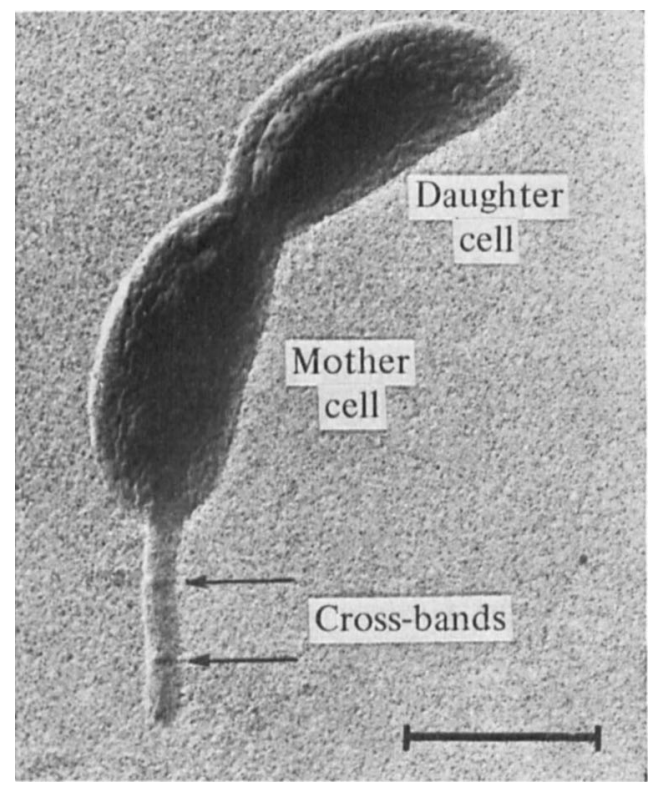

Fig. 7. Caulobacter NCIB 9083 cell showing cross-bands. Gold/palladium shadowed electron micrograph. Bar marker represents $1 \mu \mathrm{m}$. 
unit showed sequential waves of swarm cell production (Fig. 6). The peaks indicate the number of swarm cells produced per mother cell and the concomitant generation times. The number of turns of the homogeneous mother cell population is therefore precisely known.

Electron microscopic examination of the mother cells removed from the filter after three generations showed that less than $0.03 \%$ of the population possessed cross-bands (Fig. 7). Thus there is no clear relationship between swarm cell production, generation time and crossband formation.

This finding was further substantiated by analysis of homogeneous swarm cell populations followed through three generations by particle counting/cell volume distribution analysis and electron microscopy. Cross-bands did not appear during the first three generations and thus they are not obligately linked to the cell cycle. In both systems, however, when crossband formation occurred it did so throughout the stalked population indicating that cross-band formation may be a response to environmental stimuli.

In conclusion, the modified Helmstetter-Cumming technique (Helmstetter, 1969), as described, facilitates the following: (i) the maintenance of a homogeneous mother cell population without contamination by daughter cells, thus allowing the determination of the 'fate' of the mother cells with respect to time, i.e. ageing effect; and (ii) the study of the effect of environmental changes on stalk synthesis, cross-band formation and swarm cell production.

\section{REFERENCES}

Helmstetter, C. E. (1969). Methods of studying the microbial division cycle. Methods in Microbiology 1, 327-363.

Kurn, N. \& Shapiro, L. (1975). Regulation of the Caulobacter cell cycle. Current Topics in Cellular Regulation 9, 41-63.

Newton, A. (1972). Role of transcription in the temporal control of development in Caulobacter crescentus. Proceedings of the National Academy of Sciences of the United States of America 69, 447-451.

PoindeXter, J. S. (1964). Biological properties and classification of the Caulobacter group. Bacteriological Reviews 28, 231-295.

ShapIRo, L. (1976). Differentiation in the Caulo- bacter cell cycle. Annual Review of Microbiology 30, 377-407.

Shapiro, L., Agabian-Keshishian, N. \& Bendis, I. (1971). Bacterial differentiation. Science 173, 884-892.

Staley, J. T. \& Jordan, T. L. (1973). Cross bands of Caulobacter crescentus stalk serve as indicators of cell age. Nature, London 246, 155-156.

Wood, N. \& ShapIRo, L. (1975). Morphogenesis during the cell cycle of the prokaryote, Caulobacter crescentus. In Results and Problems in Cell Differentiation, vol. 7, pp. 133-149. Edited by J. Reinert \& H. Holtzer. Berlin and New York: Springer-Verlag. 